DOI: http://dx.doi.org/10.20435/multi.v21i49.655

\title{
Paraná: escravização, região, conflitos nas relações sociais - Campos Gerais (século XIX)
}

\author{
Paraná: enslavement, region, conflicts in the social \\ relations - Campos Gerais $\left(19^{\text {th }}\right.$ century)
}

Oseias de Oliveira ${ }^{1}$

Neide dos Santos Rodrigues ${ }^{2}$

${ }^{1}$ Professor Doutor do Programa de Pós-graduação em História. Universidade Estadual do Centro-Oeste (UNICENTRO), Irati, Paraná, Brasil. E-mail: oseias50@yahoo.com.br

${ }^{2}$ Mestre em História pela Universidade Estadual do Centro-Oeste (UNICENTRO), Irati, Paraná, Brasil. E-mail: nesaro67@gmail.com 


\section{RESUMO ABSTRACT}

Mesmo que, no imaginário do Paraná, persista a ideia de que sua formação é resultado da imigração europeia, sabemos que ele não fugiu à regra do Brasil: seu desenvolvimento teve relevante participação de escravizados africanos e seus descendentes. A História do Paraná, que é a história daqueles que construíram esse

Estado, invisibilizou a contribuição dos negros e, por consequência, as relações sociais entre senhores e escravizados.

Foi muito importante a utilização de documentos jurídicos, em nossa pesquisa - principalmente o processo-crime - para entender como se davam essas relações.

Fundamentados em Michel de Certeau quando fala sobre organização de espaço e delimitação de um campo, campo esse simbólico, construído pelos escravizados ao ocuparem lugares, desempenhando papéis, tornando-os sujeitos sociais, nosso intuito é enfatizar as relações sociais, muitas vezes conflitantes, entre escravizados e escravizadores no Paraná, nos Campos Gerais do século XIX, bem como o significado da região nesse contexto.

PALAVRAS-CHAVE escravização
região
conflitos
Same that in the Parana's imaginary persists the idea that their formation is result of European immigration, we know he didn't run of the rule of Brazil: its your development has relevant participation of Africans eslaved and their descendants. The history of Paraná that is the story of those who built this State, invisibilizou the contribution of blacks, and consequently, the social relations between masters and slaves. It was very important the use of legal documents, in our research, mainly criminal proceedings, to understand how to give these relations. Based on Michel de Certeau when he talks about space organization and delimitation of a field, that field, symbolic, built by slaves to occupy places, playing roles, making them social subjects, our aim is to emphasize the often conflicting social relations between slaves and slavers in Paraná, in the Campos Gerais, 19TH century, and the meaning in the context region.

\section{KEY WORDS}

enslavement

region

conflicts 


\section{INTRODUÇÃo}

Quando refletimos sobre o Paraná, não podemos esquecer que o processo de construção econômica, social e simbólica desse Estado foi produzido pela participação de várias populações, dentre elas diversas etnias europeias com configurações diversificadas de cultura. Além disso, os africanos e os afrodescendentes contribuíram, efetivamente, em muitas áreas e espaços, como na política, na engenharia, na medicina e nas manifestações culturais, religiosas e artísticas, ou seja, em todas as esferas de constituição desse Estado.

Podemos citar algumas dessas contribuições (SOUZA, 2011): na literatura, temos a escritora Laura Santos, considerada a "Pérola Negra no Paraná"; o escritor Palminor Rodrigues Ferreira, conhecido por "Lápis", foi também compositor, percussionista, violonista e considerado um dos mais representativos compositores paranaenses; Mestre Waltel, com mais de 500 composições em sua carreira, incontáveis arranjos e participações nas trilhas sonoras da TV e do cinema, sendo uma das mais famosas o tema do filme "A Pantera Cor de Rosa"; na linguagem, algumas palavras de origem africana utilizadas no Paraná: carimbo de origem ambundo, significa "sinal", "marca", "selo"; gibi de origem fon, significa "menino negro"; moringa, de origem chinchungue (língua presente em Moçambique), significa "bilha" ou "vaso alongado, feito geralmente de cerâmica, de gargalo estreito, com ou sem alça, para conter água", entre outras; na mineração e agricultura: técnicas da extração do ouro e de produção do açúcar sólido feito da cana numa época em que a maioria dos povos europeus fazia açúcar de beterraba; a produção do café (cuja origem é a Etiópia); conhecimentos de geometria fractal em tranças Nagô (povos africanos que falavam Yorubá, essa civilização já dominava a metalurgia).

A economia do Paraná perpassou pela mineração, pecuária, indústrias extrativas do mate e da madeira, lavoura de subsistência 
e envolveu sujeitos cuja faina tinha como resultado a produção de riquezas. Essa produção determinou espaços de convivência multifacetados e de muita luta.

O núcleo da história do Paraná foi delimitado em amplos espaços regionais. Ao longo do século XVIII, sua constituição era de uma sociedade campeira, patriarcal, escravista, latifundiária e ancorada na criação e na invernagem do gado nas fazendas dos Campos Gerais: na primeira metade do século XIX, nas atividades de extração e exportação de madeira e da erva-mate para os mercados do Prata e do Chile; na segunda metade do século XIX, fixou um novo sistema de colonização, objetivando a produção de subsistência.

Apesar de não ser de grande expressão o número de escravizados na composição demográfica do Paraná, não se pode ignorá-los para compreender a estrutura econômica e social da região, uma vez que foi uma sociedade em que a mão de obra escravizada representou um relevante fator de produção. Gutiérrez (2006, p. 120) diz que "a introdução do escravo provocou no Paraná diferenciações contundentes na produção, acumulação, disponibilidade de crédito, domínio da terra, criação de gado, segmentação social e acesso ao poder", cujas hierarquias, em relação à distribuição da terra e dos escravizados, evidenciava uma sociedade altamente estratificada, no núcleo da qual, retalhando as classes e promovendo dinamismo à economia, estava o escravizado.

Essa estrutura econômica, em que o escravizado teve um desempenho diferenciador na formação da riqueza e no desenvolvimento social, foi marcada pelo controle social, tanto por parte dos escravizadores, quanto das autoridades provinciais. Esse controle se efetivava através dos castigos físicos, das prisões e da criação de regulamentos, pois os escravizados eram tachados de "bárbaros" e "violentos" pelos jornais da época, bem como africanos "incorrigíveis" pelo chefe de polícia (PENA, 1999, p. 95). Essas declarações de gênero racista nasceram como fontes que dão 
legitimidade ao controle social, por outro lado, os escravizados respondiam a esse controle, na maioria das vezes, com rebeldia, enfrentamento astucioso e, frequentemente, praticando crimes.

No período da escravização, pelas diversas formas de controle utilizadas pela sociedade na preservação da ordem referentes tanto aos enfoques sociais, quanto aos econômicos, temos que compreender onde acontecia a provocação do ponto de ruptura, decisivo nessa relação de dominação com a culminância da condenação de um escravizado à morte. Isso só é possível se captarmos a interpretação dada às leis e aos códigos que regulamentavam a criminalização, entendendo, tanto quanto possível, a base em que tais códigos se apoiavam.

\section{RELEVÂNCIA DO ESTUDO DE DOCUMENTAÇÃO JURÍDICA}

Se olharmos com atenção a Constituição de 1824, perceberemos que ela omitiu partes da população, ao passo que o Código Criminal, pelo contrário, objetivou englobar aqueles que não eram amparados pela Constituição de 1824. Logo, é importante pesquisar, fazer análise de processos-crime, uma fonte repleta de particularidades. Todo processo tem fisionomia própria, descoberta na expressão dos autos, na grafia esmerada ou ilegível do escrivão, no jeito de grafar uma linha para inutilizar a página em branco. Apresenta uma trama de signos impostas à primeira vista, mesmo antes de uma leitura mais rigorosa. "Na sua materialidade, o processo penal como documento, diz respeito a dois 'acontecimentos' diferentes: aquele que produziu a quebra da norma legal, e outro que se instaura a partir da atuação do aparelho repressivo" (FAUSTO, 1984, p. 21). Este último objetivava reconstituir um fato acontecido, a fim de estabelecer a "verdade" em que o resultado teria como ação, punição ou absolvição de alguém.

Todavia a relação entre os elementos que compõem o processo-crime, o aparelho policial-judiciário, os diferentes atores e 
o acontecimento delituoso, não é linear, por isso não se pode entendê-lo por meio de critérios de verdade. De certa forma, os autos mostram duas faces: o crime e a luta que se estabelece para punir, graduar a pena ou absolver. Tudo isso nos auxilia a compreender a quais pontos de um processo devemos estar mais atentos. Ainda, podemos extrair desses documentos a fala dos personagens, que é sempre restaurada como ponte para reconstruir existências, diversas vezes escondidas. Eles possibilitam não só dar voz a um silêncio, mas modificar algo que tinha seu estatuto, sua função direcionada a outra ocorrência e que funciona de modo diferente.

No entanto a legislação, de forma geral, procurava proteger mais o escravizador do que o escravizado, pois este, como fonte de lucros enquanto objeto de comércio e mão de obra produtiva, era preservado de qualquer contestação; e o mesmo acontecia com a escravização. 0 governo econômico dos senhores nada mais era, portanto, que o equilíbrio entre a produção lucrativa, a sobrevivência do escravizado e a continuidade do domínio senhorial.

Então, a pena de morte como sistema de punição para uma classe que representava parte relevante dos meios de produção, não se justificava quando vislumbrada somente a lógica do investimento que significava. Mas temos que compreender o processo social que impunha condições sobre o uso da lei no que se refere às relações sociais e aos espaços nos quais aconteciam suas aplicações.

Isso fica evidente com a pesquisa de Pena (1999) sobre a escravização em Curitiba no período de transição para o trabalho livre, na segunda metade do século XIX. Ele expõe que os escravizados representavam uma parte minoritária da população curitibana, tornando, assim, alvo fácil de discriminação. Ele percebeu as evidências deixadas pelos próprios escravizados nos processos criminais, numa documentação cível diversificada, experiência bem marcada das imagens que o discurso provincial permitia transparecer. Ele explicita que não nega o quadro de violência e 
preconceito que, certamente, assinalou diariamente a sociedade escravista curitibana, como também não nega a ação dos escravizados, confirmando a ideologia posta, ou seja, escravizados que escravizavam e feitores na condição de escravizados que exerciam violência em seus trabalhos.

O autor imergiu na documentação cartorial, no âmago "desse universo de violência, de comportamentos e posturas bem distintas da passividade e alienação que certamente alguns escravos por coação apresentavam" (PENA, 1999, p. 185). Assim sendo, compreendendo que os escravizados, mesmo numa situação difícil no espaço de escravização, conseguiram atuar e interferir no direcionamento de suas vidas.

Esse autor narra os diferentes usos da lei e, também, a forma de agir das autoridades policiais no seu cumprimento, no que diz respeito a escravizados e escravizadores. Diz ele que, nas últimas décadas da escravização brasileira, a lei e a ação policial - reais colaboradoras do poder de dominação senhorial - para controlar os escravizados, tinham papel dúbio, demonstrado pela conduta antagônica de certos escravizados ou pessoas que, no dia a dia, mantinham relações com eles.

Como exemplo disso, o artigo 85 do título X ("sobre vozerias e alaridos") da lei no 79, de 11 de julho de 1861, estabelecia a proibição para o caso de juntar-se dentro da povoação, nas ruas, praças ou dentro de casa, escravos com tambores e cantorias: penas, sendo dentro de casa, de oito mil réis de multa, pagos pelo inquilino ou senhorio da propriedade que o permitir e, sendo nas ruas, serão os mesmos dispersados. Já o artigo 92 era o mais enfático ao não "consentir ajuntamento de escravos em qualquer casa: pena de dez mil réis". Os mesmos artigos são publicados, sob os números 92 e 99 respectivamente, quando da reedição da lei 16 anos depois (Decreto n. 491, de 14 de abril de 1877). Essas leis que proibiam certas ações dos escravizados eram questionadas, muitas vezes desobedecidas por homens livres, comerciantes 
e donos de bares ou tabernas e, nem por isso, eram advertidos (PENA, 1999, p. 135).

Pena (1999) relata ainda vários acontecimentos em que a lei, de certa maneira, não foi cumprida: em São José dos Pinhais, numa casa de bilhar, um pardo escravizado se desentendeu com o policial ferindo-o com um facão. Notou que, em nenhum momento do processo, foi questionada a presença do escravizado no jogo, nem pelo representante de polícia nem pelo promotor público, que arquivou o processo por achar que era uma "questão particular"; a multa sequer foi aplicada ao proprietário.

Em outro processo, havia o relato de uma briga entre um escravizado de nome José com Paulo José da França, em frente de um estabelecimento de secos e molhados no distrito de Votuverava, onde estavam às bordoadas um com o outro. $\mathrm{Na}$ briga, o escravo caiu e, ao se levantar, apossou-se de uma faca e desferiu três facadas em Paulo José França, sendo que o motivo da desavença era que ambos tinham bebido muito, estando meio atordoados, segundo testemunhas. Novamente, ele identifica o não cumprimento da lei, pois, desde 1829, quando da publicação do primeiro livro de posturas do século XIX da Vila de Curitiba, até a publicação das posturas do decreto n. 797, de 24 de outubro de 1884 , aos escravos estavam vedados o uso e a posse de quaisquer tipos de armas. As penas para tal infração variavam no tempo, porém nesse caso não teve multa nem advertência por parte da promotoria e do juízo municipal.

No entanto tal processo não pôde ser arquivado porque Paulo José França faleceu em função do ferimento da briga e, por isso, o escravizado José foi pronunciado pelo Juiz Municipal, mas conseguiu fugir ajudado pelo seu escravizador. Aqui entra em questão o prejuízo econômico que o escravizado daria ao escravizador se fosse preso: além de ficar sem a prestação de serviço, teria que pagar multa pela posse de armas para seu escravizado ficar livre da prisão (PENA, 1999). 
Diante do exposto, referente a esses processos, salientamos que na Curitiba provincial as inter-relações não eram tão pacíficas, mas com certa dose de violência, na maioria das vezes com escravizado envolvido. Foi no íntimo dessas relações impregnadas de enfrentamentos perspicazes que, por diversas vezes, o escravizado conseguia, nem que fosse por algum tempo, tramar espaços de autonomia: quando utilizava o dispositivo do arbitramento ${ }^{1}$; ao manipular e utilizar a lei a seu favor, através de ações cíveis de liberdade; a procura pela justiça diante da ameaça de venda que contrariava seus desejos; a esperteza de alguns escravizados ao negociarem o preço de sua libertação. Ainda, temos que os processos criminais vislumbraram os pontos limites do sistema de escravização e arquivaram uma história cheia de lutas cruéis nas quais a vitória nunca teceu heróis.

Com esses exemplos, podemos perceber que os escravizados mantinham estreitas relações não só entre si, mas com outras pessoas de condição social diferente, conseguindo assim, algumas vezes, atingirem seus propósitos e saírem vitoriosos.

Fernando Franco Neto, em seu texto sobre Senhores $e$ Escravos no Paraná Provincial, mostra que as relações existentes entre os escravizadores e os escravizados excediam as fronteiras das relações de produção, atingindo a própria natureza social e estrutural do sistema. As legislações protegiam e confirmavam a "dominação dos senhores sobre os escravos", as quais mantiveram e fortificaram esse regime pelo uso das leis proibitivas quanto às atividades dos escravizados. Segundo Franco Neto (2011, p. 138), em decretos e leis publicados no ano de 1862, encontramos artigos referentes à proibição imposta pela sociedade aristocrática paranaense: art. 105 se refere à proibição para que os escravos tirem esmolas para sua liberdade, sem licença prévia dos seus senhores;

${ }^{1}$ Arbitramento era ação cível que o escravizado impetrava, quando seu proprietário
não concordava com o valor proposto por ele, como indenização para sua alforria. 
art. 67 proíbe alugar casas a escravos; art. 68 proíbe os escravos de andarem pelas ruas depois do toque de silêncio, sem bilhete de seus senhores, não sendo por motivos justos; art. 69 proíbe dar couto a escravos; art. 70 proíbe comprar qualquer coisa a escravo que não esteja autorizado por seu senhor; art. 71 proíbe receber, guardar ou tomar como penhor qualquer objeto de escravo; art. 72 proíbe o ajuntamento de escravos em qualquer casa; e, art. 73 penaliza os senhores que abandonarem os seus escravos.

Nosso interesse é perceber certos atos violentos presentes na escravização paranaense, os quais aconteciam principalmente nas situações limites cujos resultados quase sempre eram assassinatos e pena de morte. Devemos lembrar que não podemos desviar do caminho, o qual nos leva ao foco das relações que antecederam esse momento, ou seja, a discussão sobre a questão da escravização do Paraná nos anos finais desse regime.

Nesse panorama permeado por ações de violência, a maior parte da economia era produzida pelo trabalho dos escravizados, em que muita caminhada foi organizada e determinou lugar próprio, além de posições demarcatórias de inter-relações entre os caminhantes nas diversas regiões. De um lado, os escravizados na execução das tarefas impostas: colheita, soque, transporte, viagem por caminhos e trilhas, domas de animais, plantio, artesanato, entre outras; do outro, seus proprietários: como vigias, dando ordens, muitas vezes opressores, castigadores, delimitam ao longo de suas trajetórias regiões simbólicas de poder, hierarquia, violência, submissão ou resistência, num contorno geográfico em que descreve práticas cotidianas que determinam fronteiras sociais e simbólicas.

Podemos perceber a delimitação de região quando Pena (1999, p. 122) mostra o "potencial de manipulação do escravo contido no ato de compra e venda", ao citar,

[...] entre outras fontes, o anúncio de que uma pessoa que possui um escravo, moço e robusto sem vício algum, 
deseja trocá-lo por uma escrava nas mesmas condições, convindo que, antes de realizar-se a transação, um e outro escravo fiquem a contento. Será um meio seguro para um negócio consciencioso. (PENA, 1999, p. 122-123).

Observa-se nesse anúncio que o proprietário reconhece a habilidade de ação e intervenção do escravizado no próprio ato de sua negociação e na certeza de conseguir a transação. Isso evidencia a determinação de fronteira social e simbólica demarcada pelo escravizado quando sugere critérios para a transação de seu corpo. Nessa simples notícia de troca de escravos, percebemos os caminhos que eles ousaram traçar com certos apontamentos de seus anseios satisfeitos e, com isso, demarcaram regiões.

0 discurso provincial adotado pelo Brasil não tinha como apagar seu passado escravista. Parte da elite brasileira tinha certo temor sustentado pela lembrança dos quilombos, em que o escravizado de vítima do meio se transformava em provocador da violência ao alimentar os preconceitos da minoria branca. Inclusive, segundo essa elite, a população mestiça também não inspirava confiabilidade e, por isso, não se reconhecia nesses indivíduos capacidade moral para realizar os grandes propósitos nacionais de colonização e de conquista do território. Além disso, o negro - que fazia parte de um sistema que necessitava ser exterminado - era recriminado, acusado de ser culpado do descrédito do trabalho e sem talento para tarefas significantes tão urgentes naquela ocasião.

Por conseguinte, a recomendação se formalizava numa prescrição de progresso, em que o imigrante branco, livre, pacífico e trabalhador seria a via de colaboração para branquear raça e trabalho, ou seja, extinguir as manchas da sociedade. Priorizavase, então, substituir e renovar a mão de obra nacional e de cor. 0 apregoado em nível nacional teve ecos no Paraná Provincial, deixando evidente a busca pelo embranquecimento racial, com o intuito de uma maior coesão política e aventando um futuro livre 
dos "vícios de origem" e do contato com a escravização (PENA, 1999). Essa ideia de progresso em torno de diferentes normas e valores ou de diversificadas utilizações e interpretações dadas a significados sociais gerais com base na discriminação racial provocava conflitos.

\section{REGIÃO NO CONTEXTO DAS RELAÇÕES SOCIAIS}

Diante do exposto, nossa percepção coloca regiões nas relações sociais - harmoniosas ou conflituosas - estabelecidas diariamente entre os sujeitos, pois Certeau (1980, p. 200) refere que "uma prática de espaço, [...], tem a ver com as táticas cotidianas". Mas as várias regiões, simbólicas ou não, de cultura, poder, submissão, resistência, relações sociais são:

[...] essas aventuras narradas, que ao mesmo tempo produzem geografias de ações e derivam para os lugares comuns de uma ordem, não constituem somente um 'suplemento' aos enunciados pedestres e às retóricas caminhatórias. Não se contentam em deslocá-los e transpô-los [...]. De fato, organizam a caminhada. (CERTEAU, 1980, p. 200).

Em cada instante histórico, os discursos são elaborados de forma a proporcionar confiança naquele que discursa, como também aumentar a eficiência discursiva. Temos que perceber como tais discursos se internalizam ou excluem, como procuram uma origem num entrelaçamento de saber autêntico. No que concerne ao território paranaense, são veiculadas nas falas das elites e políticos que o Paraná moderno é sinônimo de branquitude europeia ${ }^{2}$, é ausência ou nulidade de negros, mestiços e índios,

2 Dentre os autores que tratam do assunto destacamos WACHOWICZ, Rui Christovam. História do Paraná. 2. ed. Ponta Grossa: Editora UEPG, 2010; SCHMIDT, Maria Auxiliadora M. S. História do cotidiano paranaense. Curitiba: Letra Viva, 1996; SANTOS, Carlos Roberto Antunes dos. Vida material e econômica. Curitiba: SEED, 2001; NADALIN, Sérgio Odilon. Paraná: ocupação do 
com deslocamentos políticos e ideológicos, especificando espaços pelas realizações humanas a eles imputadas. Sobre isso Michel de Certeau expõe:

[...] a 'região' vem a ser, portanto, o espaço criado por uma interação. Daí segue que, num mesmo lugar, há tantas 'regiões' quantas interações ou encontros entre programas. E também que a determinação de um espaço é dual e operacional, portanto, numa problemática de enunciação, relativa a um processo 'interlocutório'(CERTEAU, 1980, p. 212).

Nessa busca da consolidação e modernização do Paraná Provincial, através das falas hegemônicas dos interlocutores progressistas, ao internalizarem em diferentes grupos sociais, o mito do branqueamento, a ideologia de que a cor preta era uma nódoa na sociedade, foram criadas regiões. Tais ditos, presentes em vários segmentos, delineavam espaços simbólicos e produziam "relatos cotidianos", cuja determinação era a anuência da produção e do fazer, demarcando "lugares". "As operações de demarcação", constituídas com frações advindas de "histórias anteriores [...] esclarecem a formação de mitos, como tem também a função de fundar e articular espaços", com vistas ao pleno desenvolvimento dos "lugares" sociais (CERTEAU, 1980, p. 208). Isso implica que os significados da convivência social, várias vezes, manifestam aos sujeitos históricos os "espaços" nos quais os embates de classe e outros conflitos presentes numa sociedade específica, revestem-se de uma posição política mais contundente, ou seja, possivelmente transformadora.

território, população e migrações. Curitiba: SEED, 2001; SCORTEGAGNA, A.; REZENDE, C. J.; TRICHES, R. I. (Org.). Paraná espaço e memória: diversos olhares histórico-geográficos. Curitiba: Bagozzi, 2005. 


\section{UM PARANÁ DIFERENTE?}

Muitos documentos e monumentos, como o catálogo seletivo de documentos referentes aos africanos e afrodescendentes livres e escravos, que se encontra no Arquivo Público do Paraná, apresentam 1.104 correspondências oficiais, como requerimentos, solicitações, circulares e ofícios, entre os anos 1853 a 1888. Nessas correspondências, podemos localizar o escravizado nos mais diferentes locais, existindo o registro da presença de negros escravizados em todos os espaços sociais: nas fazendas de gado, na produção econômica (cuja base era a subsistência), na atividade de tropeirismo, na extração e transporte da erva-mate, na extração da madeira, nos trabalhos domésticos, na construção de estradas e nos artesanatos, estando presentes também na Guerra do Paraguai. Eram presenças marcantes, também na zona urbana: nas cidades dos planaltos, principalmente na Vila de Curitiba, frequentando bares, armazéns comerciais, salas de jogos e espaços oficiais de justiça.

Ferrarini (1971) aponta, como outros autores ${ }^{3}$, um Paraná não tão diferente como o apregoado, porque esse Estado é composto por características específicas, dentre as quais as étnicas fazem parte, necessitando serem percebidas, expostas, como também as diversas vozes e culturas devem ser evidenciadas. É relevante distinguir a presença da classe dominante, da maneira como os escravizados imaginavam e estabeleciam aquele mundo e, concomitantemente, compreender que os escravizados elaboravam seu próprio espaço, com alguns aspectos semelhantes,

\footnotetext{
${ }^{3}$ Além de Sebastião Ferrarini, podemos citar: BRAZ, Fábio Cézar. História do Paraná: das origens à atualidade. Arapongas, PR: El Shaddai, 2000; HARTUNG, Miriam. Muito além do céu: escravidão e estratégias de liberdade no Paraná do século XIX. Topoi, v. 6, n. 10, jan./jun. 2005; FRANCO NETO, Fernando. Senhores e escravos no Paraná provincial: padrões de riqueza em Guarapuava (1850/1880). Guarapuava, PR: UNICENTRO, 2011.
} 
mas outros diferentes, em relação a outras províncias, mesmo sob a violência e as difíceis situações da servidão. Desse modo, a compreensão que tinham de sua posição nunca deve ser restrita às leituras dos dominadores de tal situação.

Como escreve Certeau (2002, p. 16):

[...] o real que se inscreve no discurso historiográfico provém de determinações de um lugar. Dependência com relação a um poder estabelecido [...], jogo com os símbolos e as referências que legitimam a autoridade [...], são relações efetivas que parecem caracterizar este lugar da escrita.

Essas relações efetivas caracterizam também, de certo modo, a violência descrita em diversos lugares, como por exemplo nos Campos Gerais.

\section{CONSIDERAÇÕES FINAIS}

A ocupação das terras dos Campos Gerais teve início na primeira década do século XVIII por apresentar paisagens apropriadas para o desenvolvimento da pecuária, que veio a ser rota do tropeirismo.

Em 1730 foi construído o caminho que ligava Viamão a Sorocaba. Desde então, a conexão do sul com todas as outras partes da colônia foi intensificada, pois a estrada, que ficou chamada de Caminho de Viamão, ligava as terras do Rio Grande do Sul às de São Paulo, atravessando esses campos. Os moradores do lugar desempenhavam a função de mediadores, viajavam para o Rio Grande a fim de comprar os animais e os alocar para suas terras atravessando esses campos, os quais, depois de descansados e engordados, eram revendidos em Sorocaba, como também trabalhavam na criação de gado. Essa região, na primeira metade do século XIX, "era a área que mais concentrava" escravizados, "os quais eram 'mercadorias' bastante acessíveis tanto no preço quanto na oferta" (PORTELA, 2007, p. 2). 
Na Província do Paraná, na região dos Campos Gerais, no auge do tropeirismo, entre os anos 1860 e 1877, as fazendas de invernagem estavam no auge. Representavam verdadeiras autarquias, produzindo tudo que precisavam. A família fazendeira era patriarcal, estruturada por um núcleo formado pelo fazendeiro branco e sua família; pelos arredores se alojavam os escravizados, agregados, índios, negros, mestiços, concubinas, filhos ilegítimos do proprietário (HARTUNG, 2005). Suas especificidades construíram um novo mundo social e econômico.

O lugar dividido, de acordo com Certeau, “é também um domínio dos lugares pela vista. A divisão do espaço permite uma prática panóptica a partir de um lugar de onde a vista transforma as forças estranhas em objetos que se podem observar e medir, controlar e 'incluir' na sua visão" (CERTEAU, 1980, p. 100). A disposição hierárquica das pessoas nessas fazendas permite ver longe, ou seja, prever, antecipar-se pela leitura do espaço. Nesses ambientes, os mecanismos de dominação presentes nessa relação social combatem as práticas heterogêneas, as quais são "as maneiras de fazer" de quem vivia nas periferias desse núcleo.

Nessas estâncias, o trabalho nos currais, de montaria e outros com o gado eram executados prioritariamente pelos homens livres, pelos peões. Os escravizados dedicavam-se à agricultura de abastecimento, baseada em arroz, feijão e fumo, além do artesanato, não sendo uma regra, pois vamos encontrar alguns escravizados peões, domadores, condutores de tropas, entre outras funções.

Além dos currais e povoados, os Campos Gerais deixaram de ser apenas lugar de passagem para zona produtora. Os próprios tropeiros tomavam a iniciativa, investindo na requisição de sesmarias que tinham por objetivo aumentar as tropas que seguiam para Sorocaba e para a engorda dos animais vindos do sul. Cacilda Machado diz que:

[...] o dinamismo econômico do planalto paranaense da passagem do século XVIII para o XIX pode ser avaliado pela 
riqueza das fazendas dos Campos Gerais, pelo movimento de expansão em direção aos Campos de Guarapuava e Palmas, pelo intenso comércio entre o planalto e o litoral, especialmente ao longo do Caminho do Viamão. (MACHADO, 2008, p. 48).

Miriam Hartung (2005, p. 148) constata que, "ao lado das famílias de agregados, o escravizado constituiu, portanto na força propulsora da pecuária”. Para ela, “o ‘braço escravo', de africanos e seus descendentes, viabilizou a existência dos 'potentados' que as fazendas de criação e invernagem dos Campos Gerais paranaenses, representaram". Nesses Campos, em determinados períodos e locais, o escravizado significou parte estimável da população. Como em Palmas, por exemplo, em 1858, os escravizados constituíam 38\% da população. As estatísticas populacionais do Paraná Provincial, dos Campos Gerais, da cidade de Palmeira e Ponta Grossa, embora não muito confiáveis, indicam a grande relevância que a presença do escravizado significou nessas paragens. Ainda mais, a posse de escravizados representou, em períodos específicos, riqueza e poder.

Portanto, com o crescimento regional das atividades produtivas, Guarapuava começa a fazer parte da rota de comércio interno da Colônia, comercializando animais "nas principais praças de venda do País".

Os donos dessas fazendas se estruturavam de tal forma que, praticamente, tudo que precisavam era produzido ali, sendo a economia de subsistência que realimentava o processo de produção dentro da propriedade, principalmente os alimentos e as roupas tecidas pelos escravizados, os quais executavam a maioria dos trabalhos nas fazendas. Por essas terras transitavam pessoas de diversas regiões do Brasil, que geraram riquezas com a criação de gado, tropeirismo e com os meios de subsistência.

A maioria desses escravizados não era africana, mas vindo de São Paulo, de Curitiba e de outros locais do Paraná, principalmente 
de crioulos nascidos nessa região, o que aponta um indicador de crescimento no interior da sociedade escravista, uma vez que, segundo Horácio Gutiérrez, pelos indicadores estudados por ele, sugere "como fator principal no crescimento da população escrava no Paraná, a formação de famílias e a criação de filhos" (GUTIÉRREZ, 2006, p. 114). Comparativamente, nas grandes propriedades, os crioulos foram numericamente mais expressivos do que nas pequenas. Com isso, a população escravizada apresenta suas especificidades regionais, mesmo que de forma geral tenha semelhanças com outras regiões, principalmente com Minas Gerais.

0 que aconteceu nessa região não difere totalmente daquelas citadas por diversos autores, em diversos lugares. Ou seja, podemos ver que a história dessa localidade, em parte, é um pouco da história de tantos outros lugares do Brasil.

\section{REFERÊNCIAS}

CERTEAU, Michel de. A escrita da história. Tradução de Maria de Lourdes Menezes. Rio de Janeiro: Forence Universitária, 2002.

. A invenção do cotidiano. Artes de fazer. Tradução de Epham Ferreira Alves. Petrópolis, RJ: Vozes, 1980.

FAUSTO, Boris. Crime e cotidiano. A criminalidade em São Paulo (18801924). São Paulo: Brasiliense, 1984.

FERRARINI, S. A escravidão negra na província do Paraná. Curitiba: Lítero Técnica, 1971.

FRANCO NETO, Fernando. Senhores e escravos no Paraná provincial: os padrões de riqueza em Guarapuava (1850/1880). Guarapuava, PR: Unicentro, 2011.

GUTIÉRREZ, Horácio. Donos de terras e escravos no Paraná: padrões e hierarquias nas primeiras décadas do século XIX. Revista de História, São Paulo, v. 25, n. 1, p. 100-122, 2006. 
HARTUNG, Miriam. Muito além do céu: escravidão e estratégias de liberdade no Paraná do século XIX. Topoi, v. 6, n. 10, p. 143-191, jan./ jun. 2005.

MACHADO, Cacilda. Cor e hierarquia social no Brasil escravista: o caso do Paraná, passagem do século XVIII para o XIX. Topoi, v. 9, n. 17, p. 45-66, jul./dez. 2008.

PENA, Eduardo Spiller. O jogo da face. A astúcia escrava frente aos senhores e a lei na Curitiba provincial. Curitiba: Aos Quatros Ventos, 1999.

PORTELA, Bruna Maria. Caminhos do cativeiro: a configuração de uma comunidade escrava (Castro, São Paulo, 1800-1830). 2007. 109f. Dissertação (Mestrado em História) - Universidade Federal do Paraná (UFPR), Curitiba, PR, 2007.

SOUZA, Marcilene Garcia de (Coord.). A África está em nós: história e cultura afro-brasileira: africanidades paranaenses. João Pessoa, PB: Grafiset, 2011. 
